\title{
Mycobacterium tuberculosis DNA in tissue affected by sarcoidosis
}

\author{
Helen M Fidler, Graham A Rook, Norman McI Johnson, Johnjoe McFadden
}

\begin{abstract}
Objective-To investigate the prevalence of Mycobacterium tuberculosis DNA in granulomatous tissues from patients with sarcoidosis and from controls matched for age, sex, and tissue by using the polymerase chain reaction.

Design-Single blind control trial.

Subjects - 16 patients with sarcoidosis who had undergone diagnostic biopsy of lung, skin, or lymph node and 16 patients with squamous cell carcinoma or Hodgkin's disease to act as controls. In addition, four lung specimens infected with $M$ tuberculosis were included as positive controls.

Results-M tuberculosis DNA was present in sarcoid tissues containing granulomas from seven of the $\mathbf{1 6}$ patients and one of the $\mathbf{1 6}$ matched controls. Two of the four specimens known to be infected with $M$ tuberculosis were positive in the controlled experiment.

Conclusion-These figures suggest that $M$ tuberculosis DNA is detected as readily in patients with sarcoidosis as in patients with frankly tuberculous tissues and imply that $\boldsymbol{M}$ tuberculosis may be linked to the cause of sarcoidosis.
\end{abstract}

\section{Introduction}

Despite considerable circumstantial evidence that the causal agent in sarcoidosis is likely to be a mycobacterium no conclusive association that might influence treatment has yet been shown. Both are multisystem granulomatous disorders, and patients commonly present with such similar symptoms that sarcoidosis was once held to be a variant form of tuberculosis. In addition to the clinical and histological similarities between the two diseases, there is much evidence from immunological, ${ }^{12}$ epidemiological,,$^{34}$ and microbiological ${ }^{56}$ studies to suggest a common cause. Patients, however, still have no specific treatment option and rely on being in the majority of patients who spontaneously recover. For the remainder with pre-fibrotic lung infiltration, about $7 \%$ will progress to respiratory failure, right ventricular failure, and death within 10 to 15 years.

One reason for the controversy surrounding the association between sarcoidosis and Mycobacterium tuberculosis is the absence of acid fast organisms on routine Ziehl-Neelsen staining of sarcoid tissues. Yet it is now becoming well recognised that pathogens may exist in forms without cell walls and may generate "slow bacterial infections" in which the organism will not be easily cultured. ${ }^{8}$ The tubercle bacillus has long been recognised to exist in various guises ${ }^{9}$ and seems able to exist interchangeably with and without its cell wall. ${ }^{10}$ When a concerted and invasive effort has been made to find acid fast rods in sarcoid tissue they seem to be present, ${ }^{5}$ and acid fast bacteria without cell walls ${ }^{11}$ and tuberculostearic acid ${ }^{12}$ have also been isolated from lesions of patients with sarcoidosis.

With the advent of the ultrasensitive polymerase chain reaction for detecting DNA in clinical samples the opportunity to unravel the debate should be available. The polymerase chain reaction was pioneered for diagnostic use,${ }^{13}$ and the detection of as few as two genomes of $M$ tuberculosis in clinical samples is now possible. This technique has been successfully applied to lung washings from patients with sarcoidosis, and $M$ tuberculosis DNA was detected in half of the samples. In addition, a further $20 \%$ of such patients had non-tuberculous mycobacterial DNA in their lung washes. A third of controls with negative cultures, however, were also positive for $M$ tuberculosis complex. This result could have been due to the inclusion of mostly elderly patients in the control group who may have been harbouring $M$ tuberculosis from a primary asymptomatic tuberculous infection, which was common in their youth. Another disadvantage of this study was that bronchial washings may not always sample only those parts of the lung specifically affected by the disease. ${ }^{14}$

We therefore set out to design an experiment with a younger, more appropriately matched control population. In addition, samples containing granulomatous lesions from patients with acute disease should be most likely to contain a causative pathogen. By using archival specimens embedded in paraffin to produce a large and immediate specimen pool, perfectly matched samples from the time of diagnosis can be easily generated. ${ }^{15}$ We therefore applied these techniques to archival tissues containing sarcoid granulomas and further investigated the viability of this widely available tissue source in research based on polymerase chain reaction techniques.

\section{Patients and methods}

PATIENTS

Samples from 36 patients who had undergone surgery and biopsy at the Middlesex Hospital between 1988 and 1991 were used. Sixteen of these were from patients with sarcoidosis who underwent biopsy of the lung (nine patients), lymph node (six patients), or skin (one patient). The diagnosis was therefore based on the histological presence of non-caseating granulomas in the tissue and failure to culture $M$ tuberculosis in addition to the clinical and radiological findings. Sixteen control subjects were matched for age, tissue, and racial origin (table I). In addition, four patients' lymph nodes seen to contain acid fast bacilli on ZiehlNeelsen staining were included as a positive control of DNA extraction and sample inhibition in our study samples. $M$ tuberculosis had been cultured from one of these. For all tissues the preservative method was immersion in buffered neutral formalin for up to 24 hours followed by embedding in paraffin.

\section{PREPARATION OF SAMPLE DNA}

Sections of $25 \mu \mathrm{m}$ were cut from each block with a sterile no touch technique, and new blades were used for each to reduce contamination. These sections were then placed in sterile $1.5 \mathrm{ml}$ Eppendorf containers and allocated a code number by the histopathology department at Middlesex Hospital. The samples were then analysed at Surrey University, where they underwent deparaffinisation, DNA extraction, and purification before polymerase chain reaction techniques. Four sections were cut from each block and analysed separately.

Deparaffinisation was performed as described else-
Correspondence to:

$B M 7$ 1993;306:546-9 
TABLE I-Details of tissues embedded in paraffin and selected from histopathology archives for detection of Mycobacterium tuberculosis

\begin{tabular}{|c|c|c|c|c|}
\hline \multirow[b]{2}{*}{ Disease } & \multicolumn{3}{|c|}{ Tissue } & \multirow[b]{2}{*}{$\begin{array}{c}\text { Mean age (range) } \\
\text { (years) }\end{array}$} \\
\hline & Lung & $\begin{array}{c}\text { Lymph } \\
\text { node }\end{array}$ & Skin & \\
\hline Sarcoidosis & 9 & 6 & 1 & $42(28-67)$ \\
\hline Negative controls: & 9 & 6 & 1 & $40(14-68)$ \\
\hline Squamous cell tumour & 6 & 4 & 1 & \\
\hline Hodgkin's disease & 4 & 2 & $\mathbf{0}$ & \\
\hline
\end{tabular}

where. ${ }^{1516}$ The samples were incubated in xylene at $56^{\circ} \mathrm{C}$ for 10 minutes and vortexed. They were then washed once in $80 \%$ ethanol and once in acetone and left to dry for 1 hour. To avoid contamination sterile reagents were used with new disposable pasteur pipettes for each addition and removal of washing solution. The steps were carried out in a fume hood subjected to ultraviolet light and hydrochloric acid washes between experiments. The samples were dried with loose lids on. To detect any contamination of samples before breaking the code, negative controls of sterile water were included with the samples in a ratio of one negative control per three samples and treated identically at each stage.

$D N A$ extraction - Sterile water $(50 \mu \mathrm{l})$ was added to each sample, which was then boiled for 30 minutes and a 3:2 (vol:vol) ratio of autoclaved $1 \mathrm{~mm}$ and $0.1 \mathrm{~mm}$ glass beads added to half fill each Eppendorf container (Stratech Scientific, Luton). After vigorous beating for 5 minutes in a minibead beater (Stratech Scientific, Luton) the tubes were pierced at the bottom with a 16 gauge sterile needle and nested in a $1 \mathrm{ml}$ microfuge tube. This was placed in a sterile universal tube and centrifuged at 14000 revolutions per minute for 4 minutes as previously described ${ }^{14}$ to elute sample DNA. The sample was then purified by using diatoms and guanidinium thiocyanate, ${ }^{17}$ but the procedure was adapted by washing only once with each reagent, thereby reducing cross contamination and still abolishing sample inhibition. The absence of inhibiting components was confirmed in a separate experiment. The sample was finally resuspended in $50 \mu \mathrm{l}$ of TRIS-EDTA buffer.

\section{POLYMERASE CHAIN REACTIONS}

Two sets of primers were used. IS6110 is specific for the $M$ tuberculosis complex and is present in multiple copies in $M$ tuberculosis, in a single copy in $M$ bovis $B C G$, and in $1-5$ copies in $M$ bovis. ${ }^{18}$ It has been validated for early diagnosis of tuberculosis. ${ }^{1319}$ Primers were designed to amplify a 305 base pair product as INS 1: 5' CGTGAGGGCATCGAGGTGGC $3^{\prime}$ and INS 2: 5' GCGTAGGCGTCGGTGACAAA 3'. Primers were made from a section of mycobacterial specific (65 kilodalton gene, $\mathrm{TB} 1$ and 2) groEL gene which is conserved among known mycobacteria but not specific for $M$ tuberculosis. ${ }^{1420}$ They produced a product of 625 base pairs: TB 1: $5^{\prime}$ GAGATCGAGCTGGAGGATCCGTACG $3^{\prime}$ and TB 2: 5' GCGGATCTTGTTGACGACCAGGG 3'.

Amplification was performed as described elsewhere ${ }^{9}$ but with a $25 \mu$ l reaction volume with $5 \mu$ l of sample added. The amplified products were electrophoresed through a $1.5 \%$ agarose gel stained with ethidium bromide and viewed under ultraviolet light. Positive controls of $12.5 \mathrm{fg}$ and $36 \mathrm{fg}$ of $M$ tuberculosis DNA were run respectively for IS6110 and 65 kilodalton primers to reflect their differing sensitivities.

For greater sensitivity we then performed Southern hybridisation and probing. By blotting the gel containing amplified product on to a positively charged nylon membrane and probing (or "hybridising") this with a heterologous labelled strand of DNA the sensitivity of detection can be increased 10-fold. ${ }^{21} 22$ Thus a gel which appears to contain no product may reveal the presence of $10 \mathrm{fg}$ of mycobacterial DNA, equivalent to less than 2 genomes. ${ }^{14}$ This procedure was performed for all specimens and both DNA products. Probes were prepared by random oligonucleotide labelling with digoxigenin of the products of the polymerase chain reaction electrophoresed through a $1.5 \%$ agarose gel, excised, and purified with Gene-Clean (Bio 101, La Jolla, California).

\section{STATISTICS}

We used double classification $\chi^{2}$ testing to assess the significance of the differences in positivity for the patients with sarcoidosis and controls.

\section{Results}

The specificity of the polymerase chain reaction primers has previously been validated ${ }^{14}$ but the sensitivity was reassessed. We found we could detect $12.5 \mathrm{fg}$ $M$ tuberculosis DNA with the IS6110 primers, but only $36 \mathrm{fg}$ with the 65 kilodalton based primers. Both products required Southern hybridisation and probing for detection. Our earlier technique of preparing samples for polymerase chain reactions from bronchial washings entailed a simple single tube protocol that minimised handling and the possibility of contamination. ${ }^{14}$ When this was applied to tissue sections, however, most samples were found to inhibit the polymerase chain reaction. To overcome this problem we used a DNA extraction procedure with guanidinium thiocyanate and diatom particles to purify the DNA. ${ }^{17}$ This procedure was found to abolish inhibition of the polymerase chain reaction for all specimens examined, as confirmed by spiking $M$ tuberculosis DNA with $5 \mu l$ of each purified sample, performing polymerase chain reaction techniques, and detecting amplification as described. Four sections from each block were analysed separately. Tissue homogenisation, DNA extraction, and polymerase chain reactions were performed in batches of 10 samples. To detect contamination occurring during preparation of samples, negative control samples containing only water were treated exactly as the tissue samples and examined by polymerase chain reaction techniques. One negative control sampled was processed for every three tissue samples examined.

Despite stringent precautions taken to avoid contamination in some batches of samples processed occasional negative control samples gave positive amplification on the polymerase chain reaction. We also found that, although samples from the same section gave consistently positive or negative amplification, serial sections from the same tissue block sometimes gave discordant results, presumably due to nonuniform distribution of mycobacteria within the tissue block. We therefore applied the following criteria to define a positive result.

Any sample for which a single section gave positive amplification for the IS6110 primers in an experiment in which all negative controls in the batch were negative was recorded as presumptive positive for $M$ tuberculosis complex DNA. Additionally, a presumptive positive result was recorded for any sample if three out of four of the sections examined were positive for the IS6110 polymerase chain reaction. As $M$ tuberculosis DNA should give positive amplification with the 65 kilodalton polymerase chain reaction we confirmed each positive result by amplification with this reaction. A final positive result was recorded only if the sample was positive with both the IS6110 and the 65 kilodalton polymerase chain reactions in an uncontaminated experiment. The code was then broken, and the results are presented in table II.

Three of the six lymph nodes affected by sarcoid and 
TABLE II-Results of polymerase chain reaction specific for Mycobacterium tuberculosis for patients with sarcoidosis and for controls

\begin{tabular}{lcccc}
\hline & \multicolumn{3}{c}{ Tissue } & \\
\cline { 2 - 4 } No of positive results & $\begin{array}{c}\text { Lung } \\
(\mathbf{n}=9)\end{array}$ & $\begin{array}{c}\text { Node } \\
(\mathbf{n}=6)\end{array}$ & $\begin{array}{c}\text { Skin } \\
(\mathrm{n}=1)\end{array}$ & $\begin{array}{c}\text { All`} \\
(\mathrm{n}=16)\end{array}$ \\
\hline Sarcoidosis & 4 & 3 & 0 & 7 \\
Control & 1 & 0 & 0 & 1
\end{tabular}

${ }^{\star} \mathrm{p}<0 \cdot 01$.

four out of nine of the lung specimens affected by sarcoid were positive for both $M$ tuberculosis complex specific DNA and the sequence from the 65 kilodalton gene. Only one of the control subjects was similarly positive, and this sample was from the upper lobe of a lung with clear apical capping suggestive of old asymptomatic infection with $M$ tuberculosis. Neither of the skin specimens was positive, and sections of lymph node from matched controls were never positive with either set of primers.

Of the four infected tissues containing acid fast bacilli, two were positive for IS6110 and 65 kilodalton sequences. These included the only sample positive on culture for $M$ tuberculosis.

\section{Discussion}

We have presented data showing that a significant proportion of granulomatous tissues from patients with sarcoidosis contain $M$ tuberculosis DNA ( $\mathrm{p}<0 \cdot 01)$. This applies to both affected lung and lymph nodes. Only one control tissue fulfilled our criteria for positivity. These results agree with those recently presented of tests that examined bronchial lavage fluid, ${ }^{14}$ in which half of patients with sarcoidosis were positive for $M$ tuberculosis DNA.

The sensitivity of $50 \%$ for samples of tuberculous tissue roughly concurs with the results from much larger studies on various clinical samples that give a sensitivity for the polymerase chain reaction of $37-80 \%$ and culture of $29-67 \% .{ }^{1323}$ The positive controls in our experiment that were negative for the polymerase chain reaction were also culture negative, and our apparent low sensitivity is consistent with previous work on clinical samples. ${ }^{14}$ This is disappointing for such a theoretically sensitive technique, but we found that tissue itself potently inhibits the polymerase chain reaction if not adequately purified, and despite our spiking experiment we may not have abolished sample inhibition. The incorporation of a modified template may have detected this.

This study has confirmed our previously reported prevalence of such DNA in sarcoid samples but had only $6 \%$ "false positivity" compared with our lavage study, in which $32 \%$ of elderly control patients were positive for $M$ tuberculosis DNA. Our one positive control specimen was lung tissue taken from a carcinoma in a region of apical fibrosis in a patient aged 45 years. This patient may have had asymptomatic $M$ tuberculosis infection in this classic anatomical site, as is well recognised in patients with chronic bronchitis, in whom it may be unmasked by treatment with steroids. Other studies that used similar techniques for diagnostic purposes give a similar genuine false positive rate. ${ }^{13}$ We attribute our low rate of false positivity to the use of age matched controls.

Other recent research is consistent with ours. Mycobacterial rRNA has been shown to be raised in sarcoid spleens..$^{24}$ Other authors have recently cultured sarcoid skin lesions and grown mycobacteria that on sequencing appear to be $M$ avium spp..$^{25}$

Not all studies using molecular techniques have produced evidence for $M$ tuberculosis as the pathogen in sarcoidosis. Bocart et $a l^{26}$ found mycobacterial DNA in only two of 16 tissues affected by sarcoid, and an accompanying editorial to their paper suggested this was strong evidence against a link. We suspect, however, that the reason for the low positivity in their experiment could be due to differences in sensitivity, and this study failed to include positive control tissue infected with tuberculosis to detect this. ${ }^{27}$ In our experience the technique used for tissue disruption and DNA extraction is critical to the success of subsequent DNA amplification. Mechanical disruption of tissue and microbial cells is far more efficient in our hands than enzyme methods. We used glass beads for mechanical disruption and included tissues infected with mycobacteria as positive controls for DNA extraction and sample inhibition. We estimated that each positive sarcoid section had as few as six genomes by comparison with positive control DNA samples, and Southern hybridisation was essential for detection. In addition, the viable DNA in tissue embedded in paraffin decreases according to the nature and duration of exposure to preservative. ${ }^{15}$ The different techniques used in hospital pathology departments before samples are tested may, therefore, affect results.

Our results suggest that $M$ tuberculosis DNA is associated with tissues affected by sarcoid with a similar prevalence to tissue infected with $M$ tuberculosis. Taken in conjunction with the wealth of circumstantial evidence based on epidemiological, ${ }^{34}$ immunological, ${ }^{12}$ and microbiological ${ }^{51112}$ data, the implication that $M$ tuberculosis is the infecting organism in this disease is becoming convincing. The results of trials of antituberculous drugs have been discouraging, but these are generally small studies that use older regimens based on isoniazid, aminosalicylic acid, and streptomycin. ${ }^{28}$ In addition, the tubercle bacillus in patients with sarcoidosis may be present in the form without a cell wall ${ }^{29}$ as a slowly growing bacterial infection ${ }^{8}$ so agents directed toward the cell wall mycolic acid such as isoniazid would be ineffective. In addition, the bacteria may exist in a "stationary phase," which is well recognised in other genera. ${ }^{30}$ These points may also explain their failure to grow in culture media but do raise the possibility that another, as yet unidentified organism, may be involved.

In conclusion, we have demonstrated the presence of $M$ tuberculosis DNA in sarcoid lung and lymph tissue and shown that archival specimens seem to be suitable for research based on polymerase chain reaction techniques. The implications of this for any study in which sample recruitment is time consuming or invasive are obvious. The evidence is now sufficient to justify a new approach that uses the polymerase chain reaction to identify patients infected with $M$ tuberculosis. A multicentre controlled trial of modern antituberculous drugs may then be performed in patients positive for the polymerase chain reaction to assess the potential for a specific, non-steroidal, curative treatment.

This work was funded by a fellowship from the Sir Jules Thorn Charitable Trust.

1 Balbi B, Moller DR, Kirby M, Holroyd KJ, Crystal RG. Increased numbers of $T$ lymphocytes with $\gamma \partial$-positive antigen receptors in a subgroup of T lymphocytes with $\gamma \partial$-positive antigen receptors in a subgroup
individuals with pulmonary sarcoidosis. $\mathcal{F}$ Clin Invest 1990;85:1353-61.

2 Foley N, Millar A, Rook G, McI Johnson N. Enhanced production of tumour necrosis factor by pulmonary alveolar macrophages in sarcoidosis and necrosis factor by pulmonary alveolar ma
tuberculosis. Clin Sci 1988;75(suppl 19):2p.

3 Brett G. Epidemiological trends in TB and sarcoidosis in the district of London between 1958 and 1963. Tubercle 1965;46:412-6.

4 Parkes SA, Baker S, Bourdillon RE, Murray CRH, Rakshit M. Epidemiology of sarcoidosis in the Isle of Man. I. A case controlled study. Thorax 1987;42:420-6

Kent D, Hank V, Elliott R. The definitive evaluation of sarcoidosis. Am Rev Respir Dis 1970;101:721-7.

6 Vanek J, Schwartz J. Demonstration of acid-fast rods in sarcoidosis. Am Rev Respir Dis 1970;101:395-9.

7 Scadding JG. The prognosis of intrathoracic sarcoidosis in England. BMF 1961;ii:1165-72.

8 Rook GAW, Stanford JL. Autoimmunity or slow bacterial infection? Immunology Today 1992;13(5):160-4.

Calmette A, Valtis J. Virulent filtrable elements of the tubercle bacillus. Ann Med 1926;19:553. 
10 Khomenko AG. L-transformation of the mycobacterial population in the process of treating patients with newly detected destructive pulmonary tuberculosis. Probl Tuberk 1980;2:18-23.

11 Graham DY, Markesich DC, Kalter DC, Yoshimura HH. Isolation of cell wall defective acid-fast bacteria from skin lesions of patients with sarcoidosis. In: Grassi C, Rizzato G, Pozzi E, eds. Excerpta medica: sarcoidosis and other granulomatous disorders. Amsterdam: Elsevier, 1988:161-4. (Vol 756.)

12 Hanngren A, Odham G, Eklund A, Hoffner S, Stjercberg N, Westerdahl G. Tuberculostearic acid in lymph nodes from patients with sarcoidosis. Tuberculostearic acid in

13 Brisson-Noel A, Aznar C, Cheveau C. Diagnosis of tuberculosis by DNA amplification in clinical practice evaluation. Lancet 1991;338:364-6.

14 Saboor SA, McI Johnson M, McFadden JJ. The use of the polymerase chain reaction to detect mycobacterial DNA in tuberculosis and sarcoidosis. Lancet 1992;339:1012-5.

15 Greer CE, Lund JK, Manes MM. PCR amplification from paraffin-embedded tissues. PCR Methods and Applications 1991;1:46-50.

16 De Wit D, Steyn L, Shoemaker S, Sogin M. Direct detection of Mycobacterium tuberculosis in clinical specimens by DNA amplification. $f$ Clin Microbiol 1990;28(11):2347-441.

17 Boom R, Soll CJA, Salumans MMM. Purification of clinical samples by use of diatoms and guanadinium thiocyanate. 1 Clin Microbiol 1990;28:495-503.

18 Van Soolingen D, Hermans PWM, De Haas PEW, Soll DR, Van Embden JDA. Occurrence and stability of insertion sequences in mycobacterium DA. Occurs, and stains: DNA polymorphism as a tool in the epidemiology of tuberculosis. $f \mathrm{Clin}$ Microbiol 1991;29:2578-86.

19 Hermans PWM, Van Soolengen D, Dale JW, Schuilema AR, McAdam RA, Catty D, et al. Insertion element IS986 from Mycobacterium tuberculosis: a useful tool for diagnosis and epidemiology of tuberculosis. $\mathcal{F}$ Clin Microbiol 1990;28:2051-8
20 Shinnick TM. The 65 kilodalton antigen of Mycobacterium tuberculosis f Bacteriol 1987;169:1080-8.

21 McFadden JJ. Principles of nucleic acid hybridization. Methods in Gene Technology 1991;1:1-14.

$22 \mathrm{McFadden}$ JJ, Knight A. DNA probes for detection and identification of bacteria. In: Grange JM, Fox A, Morgan NL, eds. Genetic manipulation. Oxford: Blackwell Scientific, 1991:97-111.

23 Manjunath N, Shankar L, Rajan L, Bhargava A, Saluja S, Shriniwas. Evaluation of a polymerase chain reaction for the diagnosis of tuberculosis. Tubercle 1991;72:21-7.

24 Mitchell IC, Turk JL, Mitchell DN. Detection of mycobacterial rRNA in sarcoidosis with liquid-phase hybridisation. Lancet 1992;339:1015-7.

25 Graham DY, Markesich DC, Kalter DC, Moss MT, Hermon-Taylor J, El-Zaatari FAK. Mycobacterial aetiology of sarcoidosis. Lancet 1992;340: 52.

26 Bocart D, Lecossier D, De Lassence A, Valeyre D, Battesti J, Hance AJA. Search for Mycobacterial DNA in granulomatous tissues from patients with sarcoidosis using the polymerase chain reaction. Am Rev Respir Dis 1992;145:1142-8

27 Fidler H. Search for mycobacterial DNA in granulomatous tissues from patients with sarcoidosis using the polymerase chain reaction. Am Rev Respir Dis (in press).

28 James DG, Thomson AD. The course of sarcoidosis and its modification by treatment. Lancet 1959; i: 1057-61.

29 Mitchell DN, Rees RJ. The nature and physical characteristics of transmissible agents from human sarcoid and Crohn's disease tissues. In: Chretien J, Marsac J, Saltiel JC, eds. Proceedings of the ninth international conference on sarcoidosis, Paris. Oxford: Pergamon, 1983:132-41.

30 Siegele DA, Kolter R. Life after log. 7 Bacteriol 1992;174:345-8.

(Accepted 9 December 1992)

\section{Demographic and social characteristics of adults with cystic fibrosis in the United Kingdom}

Sarah Walters, John Britton, Margaret E Hodson

Abstract

Objective-To obtain information about social and demographic characteristics and lifestyle of adult patients with cystic fibrosis, including those who do not attend major specialist clinics.

Design-Confidential self completion postal questionnaire to adult patients with cystic fibrosis, asking about social and demographic characteristics, social class and occupation, employment, education, insurance and social security benefits, symptom severity, and medical care.

Setting-National association for adults with cystic fibrosis.

Subjects -1052 adult members of the Association of Cystic Fibrosis Adults UK, accounting for $68 \%$ of those with cystic fibrosis in the United Kingdom population over 16 years of age and over $80 \%$ of those over 25 in June 1990.

Results - The response rate was $82 \%$ (397 women, 423 men). Most adults with cystic fibrosis were found to be living fulfilling lives into adulthood. Significantly fewer men were married or cohabiting than women (110 (26\%) men, $175(44 \%)$ women). 420 $(55 \%)$ responders were working, and of these 235 $(56 \%)$ had less than two weeks' sick leave a year. Half of those not employed gave ill health as the reason. Revealing that they had cystic fibrosis at job interviews reduced likelihood of being employed for those with mild to moderate disease. People with cystic fibrosis had been less successful than the general population in achieving $\mathbf{O}$ level or equivalent qualifications, but more successful in achieving A level or higher qualifications. Achievement of any qualifications enhanced employment prospects irrespective of disease severity.

Conclusion-Contrary to an image of chronic ill health and disability, a high proportion of adults with cystic fibrosis are living full and productive lives.

\section{Introduction}

Cystic fibrosis is the commonest serious inherited disease among white people, affecting 1 in 2500 live births in the United Kingdom. After its recognition in
$1936^{1}$ and its description as a clinical entity in $1938,{ }^{2}$ the prognosis has improved from a few months of life to a median age of survival of over 20 years. ${ }^{3}$ Over a third of cystic fibrosis patients are now over the age of $15,{ }^{4}$ and the number of patients is increasing by 100 to 120 patients a year, most of whom are adults. ${ }^{5}$ Considerable rises in the number of adult patients are forecast by the year $2000 .^{6}$

There have been few studies of adults with cystic fibrosis with respect to employment, education, housing, insurance, and other features of lifestyle, and most such studies have been based on patients attending large clinics, who may be unrepresentative of the total population with the disease. Patients attending the cystic fibrosis clinic in Melbourne were found to have a good outlook with respect to employment and social life, ${ }^{7}$ and a study at the Brompton Hospital characterising clinical and social features of patients attending its cystic fibrosis clinic found a similarly good outlook. ${ }^{8}$

Our study aimed to describe the social and demographic characteristics of adults with cystic fibrosis in the United Kingdom and the medical care they receive and to provide baseline data from which the impact of changes recently introduced into the National Health Service can be assessed.

\section{Subjects and methods}

SUBJECTS

All 1052 people with cystic fibrosis aged over 16 who were alive and known to the Association of Cystic Fibrosis Adults UK (ACFA) on 1 July 1990 were studied. Adults with cystic fibrosis become known to ACFA by transfer from the Cystic Fibrosis Research Trust's mailing list when they reach the age of 18 , or by direct referral. Many paediatricians inform the research trust of new patients with cystic fibrosis, with their family's consent, on diagnosis. ACFA membership is biased towards patients attending larger treatment centres where there is awareness of the cystic fibrosis trust, but it contains a substantial proportion of patients who would not be included in a study based on large clinics. 